systematic approach to management-in this case the managernent of production-as had been outlined by Sir Charles Goodeve. "Automation", said Mr. Diebold, "is a way of thinking, a way of 'looking at' as much as a way of doing. It is an attitude-a 'philosophy of production' rather than a particular technology of electronic devices. It is something as revolutionary in its way as Henry Ford's concept of the assembly line. It is a very simple fact that the most efficient use of machines has little to do with the most efficient division of human skills. Until recently, this was simply one of the paradoxes inherent in mechanization. With the introduction of the new concept and technology of self-regulating systems, it is no longer necessary to design the production processes around the limitations of human skills. It is here that we begin to reach the heart of the true meaning of automation."

John Diebold, who at the age of twenty-eight is described in the United States as 'the elder statesman of automation', proved to be highly conscious of his share of the responsibility for introducing this word into general currency. It is not, he said, a very beautiful one, but he has yet to find any satisfactory substitute for it. "For a long time", he added, "I have searched for a definition of automation that would be of use to me in an operational way. In the course of this conference $I$ am sure we will all gain some new insights into the problem. In the meantime, 1 offer the following for your consideration: 'Automation is a means of analysing, organizing and controlling our production processes to achieve optimum use of all of our productive resources, mechanical and material as well as human'."

The need for a scientific use of the machines which the scientists have provided was emphasized by Dr. B. V. Bowden in a paper devoted to the electronic processing of data for management. More important than a machine's ability to do arithmetic, said Dr. Bowden, is its ability to organize its data. "How many managerial decisions", he asked, "rest on numerical criteria which may have been applied consciously or unconsciously by the executives? How many of them could be made by a machine?" Listing many successful applications of electronic computers to industry, Dr. Bowden had one very tolling point to make. "We were once asked", he said, "to mechanize certain commercial calculations which had occupied five people for about three weeks every month. We found that the calculations could be done on the Manchester machine in a couple of hours; but further study showed that they could be done by hand in three hours if they were properly organized and simplified in a manner which the mathematician's analysis suggested. It is a very salutary experience", continued Dr. Bowden, "for any company which imagines that its accounting system is simple and well understood by the staff to try to programme the work so that it can be done by an accounting machine."

Besides the formulation of principles for the future, the conference was also concerned with the communication of those principles not only to present-day managers but also to those undergoing training for management. Education for management was one of the most urgent issues discussed at Harrogate, and the problems of training managers in science and scientists in management, received special attention in two sectional meetings. Among those attending there was a strong appreciation of the vital need for more trained men in the future. This need was expressed very forcefully by Mr. R. Craig Wood in a paper entitled "The Influence of the Increasing Rate of Scientific Development on Future Management Requirements". "To make progress and succeed in the technological revolution", he said, "we will need more and better human management. We must upgrade our basic human material. There is no more exacting need for human management than in the development of the individual to new skills, higher abilities, greater responsibilities. The upgraded working force will need a higher level of management. Sheer technical brilliance will be no substitute for human leadership.... Mankind ean enjoy the fruits of technical progress", concluded Mr. Craig Wood, "only so fast as it can learn to manage their production and distribution."

\section{PSYCHOLOGY AND THE FILM}

$\mathrm{A}$

ONE-DAY conference on the film in training and research in psychology and psychological medicine was held in University College, London, on October 22. This conference, which was attended by about a hundred and fifty people, was organized by the British Universities Film Council, a body founded in 1948 to promote the production, distribution and use of films in university teaching and research, and which has already organized conferences on the film in relation to language teaching, to the teaching of arts-faculty subjects, and to chemical engineering. Section $A$ of the conference dealt with films in psychology and Section B with films in psychological medicine, the morning sessions being devoted to films in training and the afternoon sessions to films in research. Although papers were read, a feature of the conference was the showing of a great number of films. This led to critical discussion on the individual films, as well as providing the most practical form of demonstration of the various functions films can fulfil.

At the commencement of Section A, Mr. A. Watson spoke of the danger of biased or false presentation through films; but, as conference members remarked during discussion, this danger is not peculiar to the film medium. A film on the cerebral cortex of the monkey was shown. Dr. M. Gunther then read a paper on babies' first feeding responses, using a film made by her and part of a film by Dr. Tinbergen on the pecking responses of a newly hatched gull. A film on cats reared in darkness, a subject which is of interest in connexion with miner's nystagmus, showed the rotations and oscillations of the eyes of cats. Another film, entitled "Warning in the Dark", showed that the capacity of some blind persons to avoid obstacles is due to their sensitive reaction to reflected sounds.

The Department of Psychology of the University of Reading has given some attention to problems of film presentation. Mr. D. Bruce, of the Department, in a paper entitled "Immediate Recall of Film Material", said that the film is suitable for memory experiments, because for these experiments meaningful, and consequently 'life-like', material is desirable, and also material the presentation of which is capable of exact repetition. He showed a film, "Fidelity of Report". Mr. S. Laner, of the same Department, is engaged in comparing the effectiveness of films with other visual media, as aids to learning. In his experiments he uses two versions of a film, and these were 
projected at the conference. One version portrayed the making of a paper barge with movement-in the normal film manner-and the other a series of static views at essential points in the operation. His experiments so far show the advantage of movement, and also of repeated film showings and of commentary. A coloured sound film, introduced by Dr. D. Fry, revealed movements of the tongue during speech of a surgical case whose cheek had been removed. It has been used in the teaching of students of physiology and of psychology, as well as phonetics.

Dr. D. Hill, presiding at the opening of Section B, said that little use has been made of films so far in psychological medicine teaching, and stressed again the need for specific objectives in teaching films. $\mathrm{He}$ asked conference members to consider whether films showing common or rare cases are the more valuable, and whother it might not be equally important to show the home as the clinical situation.

Dr. R. Mackeith introduced and provided commentary to the film "Hemispherectomy for SturgeWeber Syndrome". This film, which was silent and coloured and the tempo of which (intentionally for teaching effectiveness) was slow, showed a child patient before and after hemispherectomy. The two films next projected were sound films, speech in them being an essential part of the portrayal; they were straightforward records of interviews of patients with a doctor : "Depressive states-1", and "Folie à deux". There was little change of point of view, and a minimum amount of expression through editing. In contrast, Dr. R. Spitz's film, "Grief", showing the condition of infants consequent on separation from their mothers, was the product of a high degree of selective editing.

In the afternoon Prof. P. Russell summarized the advantages of using films when studying behaviour. Films are permanent records; they facilitate measurement (including opportunity for deciding on appropriate measurements), the forming of hypotheses, and a complete analysis. A film "Function of Parietal Lobes" showed the behaviour of monkeys after lesions had been made; there was no loss of motor power of the monkeys, or of tactile discrimination, but impairment in learning from visual cues. Another interesting film-"Animal Studies in the Social Modification of Organically Motivated Behaviour" - showed the social behaviour of rats, in various circumstances of feeding. Dr. P. Sainsbury illustrated a paper on a method of measuring spontaneous movements by time-sampling motion pictures, by a film made in the course of research. A concluding paper on the use of the film as a thematic apperception test, by M. G. Cohen-Séat, of the Institut de Filmologie, Paris, was illustrated by some films made at that Institute.

The films shown at the conference illustrated the great variety of forms of record and of communication possible through cinematography. If the conference has led to an increased awareness of this, and there. from perhaps of the value of research on the film itself, one useful purpose will have been served. Some of the films - in photography and matters of technical film detail - did not come up to the standards of the professional film-maker; but this can only emphasize the benefit which would result from better film-making facilities at universities and institutions where psychological filmas are made. The conference was well planned to show a number of ways in, which the film can contribute to psychology training and research. Credit is due to the British Universities Film Council and to its representatives, Miss G. Keir and Mr. D. Bruce, who were responsible for the detailed arrangements. C. Denis Pegat

\section{INTERNATIONAL RESEARCH IN RADIO ASTRONOMY}

$\mathrm{N}$ an account of a General Assembly of the Inter1 national Scientific Radio Union held in Sydney in 1952 (see Nature, 171, 628; 1953), reference was made to the fact that the Union had commenced the publication of some special reports on radio topies of international interest. During the past year, Nos. 3,4 and 5 in this series have been published with the financial help of Unesco, and are obtainable from the General Secretary of the Union, at 42 rue des Minimes, Brussels*.

These three reports, which deal with different portions of the field of radio astronomy, have been prepared by small sub-committees of expert research scientists working in Australia, France, Great Britain, the Netherlands and the United States, assisted by various members of the Union under the general auspices of Commission V (Radio Astronomy), of which Dr. M. Laffineur is the chairman.

Report No. 3 is entitled "Discrete Sources of Extra. Terrestrial Radio Noise", and comprises a clear sum. mary of the considerable volume of research which has been carried out, principally in Great Britain and Australia, since the inception of this field of work less than about ten years ago. The report deals in detail with the results of surveys of the distribution of sources of radiation, the effects of the ionosphere in producing scintillation and refraction, the detection of sources against background radiation and receiver noise, and the determination of their positions and angular band-widths.

The fourth and fifth reports in the series are bound in one cover. No. 4 is entitled "The Distribution of Brightness on the Solar Disk", and summarizes the progress made in this portion of radio astronomy since the publication of Report No. 1 in 1950 under the more general title of "Solar and Galactic Radio Noise". The present report (No. 4) deals with the problem of measuring the relative intensity of radio emission from different parts of the solar disk, and the results of observations carried out with receiving systems operating at centimetre, decimetre and metre wavelengths. These results are discussed in relation to a study of the physics of the Sun, which has confirmed in broad outline the conclusions drawn from optical observations concerning the solar atmosphere. The radio work has, however, arrived at the stage of providing more accurate estimates of electron temperature and density in the solar chromosphere and corona than have been available previously.

The exciting story of the prediction, and detection seven years later, of radiation from hydrogen in interstellar clouds on a wave-length of $21.1 \mathrm{~cm}$. is discussed in cold scientific language in Report No. 5, entitled "Interstellar Hydrogen". A description is given of the mechanism of excitation of the hydrogen molecule, the measuring apparatus used, and the method of determ-

* International Scientific Radio Union. Special Report No. 3 : Discrete Sources of Extra-Terrestrial Radio Noise. Pp. 56;75 Belg. fr., 11s. 0d., or 1.5 dollars. Special Reports Nos. 4 and 5 : The Distribution of Radio Brightness on the Solar Disk; Interstellar Hydrogen. Pp. $72 ; 100$ Belg. fr., 148. 6d., or 2 dollars. (Brussels:
International Scientific Radio Union, 1954.) 